\title{
EGCG inhibits growth and induces apoptosis in renal cell carcinoma through TFPI-2 overexpression
}

\author{
BIN GU, QIANG DING, GUOWEI XIA and ZUJUN FANG \\ Department of Urology, Huashan Hospital, Shanghai Medical College, Fudan University, Shanghai, P.R. China
}

Received September 15, 2008; Accepted November 6, 2008

DOI: 10.3892/or_00000266

\begin{abstract}
EGCG (epigallocatechin gallate), the major catechin found in green tea, has been shown to inhibit proliferation and induce apoptosis in many tumors. EGCG can inhibit DNMT (DNA methyltransferase) activity, and cause CpG demethylation and reactivation of methylation-silenced genes. Tissue factor pathway inhibitor-2 (TFPI-2), a member of the Kunitz-type serine proteinase inhibitor family, is inversely related to an increasing degree of malignancy. Our previous study showed that the expression of TFPI-2 and invasiveness of renal cell carcinoma had a negative correlation. Overexpression of TFPI-2 may induce tumor cell apoptosis in renal cell carcinoma. Lower expression of TFPI-2 in renal cell carcinoma was partly due to hypermethylation of the gene promoter. Herein, using MTT and flow cytometry, we demonstrated that EGCG can inhibit growth and induces apoptosis in renal cell carcinoma cell line 786-0. In addition, Western blotting and real-time RT-PCR showed that EGCG can upregulate expression of TFPI-2. Before and after EGCG treatment, real-time methylation specific PCR could not detect methylation status of TFPI-2 gene promoter in cell line 786-0. In vivo invasiveness and metastasis test did not indicate any significant differences between control and treatment group. Our results suggest that EGCG inhibits growth and induces apoptosis in renal cell carcinoma through TFPI-2 overexpression. This is the first report showing that EGCG is likely to be an effective agent for renal cell carcinoma.
\end{abstract}

\section{Introduction}

Green tea is one of the most widely consumed beverages. Generally, a typical cup of green tea contains 100-150 mg catechins, including $50 \%$ of epigallocatechin-3-gallate

Correspondence to: Dr Qiang Ding, Department of Urology, Huashan Hospital, Shanghai Medical College, Fudan University, Shanghai 200040, P.R. China

E-mail: gubinyz@yahoo.com.cn

Key words: epigallocatechin gallate, tissue-factor-pathway inhibitor 2, renal cell carcinoma, methylation
(EGCG) (1). Numerous studies have shown that EGCG possesses obvious antiproliferative, proapoptotic, antiangiogenic, antimetastatic, and cell cycle regulation activities in various in vitro and in vivo tumor models. These experimental studies together with several epidemiological studies have suggested that EGCG harbors strong anticancer and cancer preventive effects in numerous human cancers.

Hypermethylation of DNA is a key epigenetic mechanism for the silencing of many genes including those for tumor suppressors, DNA repair enzymes, and receptors. In this aberrant methylation, the cytosine of the $\mathrm{CpG}$ island in or near the promoter region of the newly synthesized DNA strand is methylated by DNMT. A study has demonstrated that the gallic acid moiety of EGCG plays a crucial role in its high-affinity, direct inhibitory interaction with the catalytic site of the human DNMT1, and its binding with the enzyme is stabilized by $\mathrm{Mg}^{2+}$ (2). Our previous study showed that overexpression of TFPI-2 may induce tumor cell apoptosis in renal cell carcinoma. Lower expression of TFPI-2 in renal cell carcinoma was partly due to hypermethylation of the gene promoter. TFPI-2 is likely to be a tumor suppressor in renal cell carcinoma. Does EGCG upregulate expression of TFPI-2 through inhibition of DNMT? Is EGCG a novel anticancer agent against renal cell carcinoma?

In the present study, we tested the above hypothesis by examining the effect of EGCG on renal cell carcinoma cell line 786-0 and expression regulation of TFPI- 2 by EGCG.

\section{Materials and methods}

Cell culture and treatment conditions. The human renal cell carcinoma cell line 786-0 was purchased from Institute of Biochemistry and Cell Biology, Shanghai, P.R. China. Cells were maintained in RPMI-1640 medium supplemented with $10 \%$ heat-inactivated fetal bovine serum, penicillin $(100 \mu \mathrm{g} / \mathrm{ml})$ and streptomycin $(100 \mu \mathrm{g} / \mathrm{ml})$ in a $5 \% \mathrm{CO}_{2}$ atmosphere. Cells were then incubated with various concentrations of EGCG (10 and $20 \mu \mathrm{M}$ ) (purchased from Boyun Biotechnology Ltd., Shanghai) or PBS buffer (as control) for 6 days. Each group was made up of 5 samples.

MTT assay. To determine the change of tumor cells number, colorimetric assay using MTT reagent was performed to detect their growth activity. The cells were incubated with MTT and dimethyl sulfoxide for $4 \mathrm{~h}$ and $10 \mathrm{~min}$, respectively. Then the cells were quantified by measuring the absorbance 


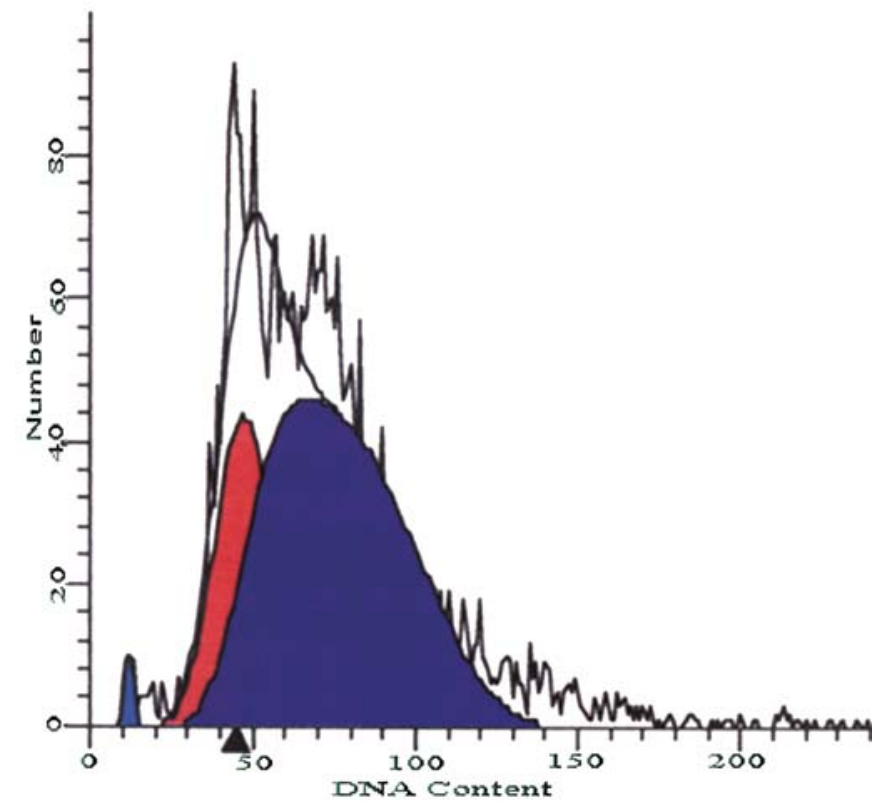

Sample: 1. G0-G1: $22.10 \%$ at 47.00, G2-M: $0.00 \%$ at 105.61

Total S-phase: $77.90 \%$, Apoptosis rate: $1.01 \%$

Figure 1. Flow cytometry revealed cell cycle S-phase rate and apoptosis rate in PBS (as a control) treatment group.

at $490 \mathrm{~nm}$. Inhibition rate $=(1-\mathrm{OD}$ value of treatment group $/$ OD value of control group) $\mathrm{x} 100 \%$.

Flow cytometry analysis. Cells were dehydrated with $95 \%$ alcohol followed by PBS. Trionx-100 (1 ml) was added to the cell line. After $10 \mathrm{~min}$, cells were centrifuged for $5 \mathrm{~min}$, $1500 \mathrm{rpm}$. Then RNAse and propidium iodide were added. Sample was filtrated by nylon network. After storaged for 20 min, cells were detected by flow cytometry (Becton Dickinson FACScalibur) which demonstrated information of cell cycle and apoptosis.

Western blotting. Total cellular protein was isolated from cells in lysis buffer containing proteinase inhibitors, and equal amount of protein were separated by SDS/PAGE and electroblotted to a nitrocellulose membrane. Immunoblotting was performed using primary rabbit anti-human TFPI-2 antibody (Santa Cruz Biotechnology, 1:400 dilution), then the protein was washed and incubated again with secondary anti-rabbit IgG (Santa Cruz Biotechnology, 1:2000 dilution) at room temperature. Protein was detected using enhanced chemiluminescence and autoradiography.

Real-time RT-PCR and real-time methylation specific PCR. Total cellular RNA was extracted by TRIzol reagent according to manufacturer's instructions. RNA was resolved in isopropanol and kept in $-20^{\circ} \mathrm{C}$ until cDNA synthesis. The final volume of the real-time RT-PCR reactions was $50 \mu 1$ and included $5 \mu \mathrm{l}$ cDNA, primers $0.5 \mu 1$ each, probe $0.5 \mu 1$, dNTPs $0.5 \mu 1$, and TaqMan enzyme $1 \mu 1$. The sample was incubated at $50^{\circ} \mathrm{C}$ for $2 \mathrm{~min}$, at $95^{\circ} \mathrm{C}$ for $10 \mathrm{~min}$, followed by 40 cycles, $95^{\circ} \mathrm{C}$ for $15 \mathrm{sec}, 60^{\circ} \mathrm{C}$ for $1 \mathrm{~min}$. All the real-time RT-PCR reactions were performed on ABI-7300 platform.

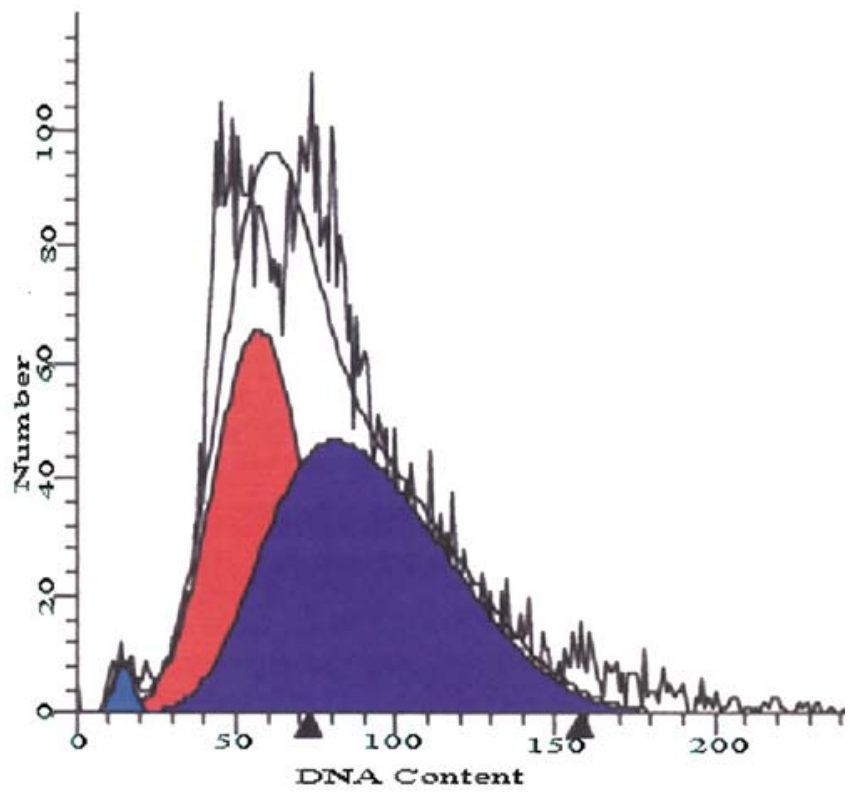

Sample: 1 . G0-G1: $40.79 \%$ at 57.25 , G2-M: $3.09 \%$ at 115.08 Total S-phase: $56.12 \%$, Apoptosis rate: $1.21 \%$

Figure 2. In EGCG $(10 \mu \mathrm{M})$ treatment group, flow cytometry revealed that cell cycle S-phase rate was lower, while apoptosis rate higher than that in PBS treatment group.

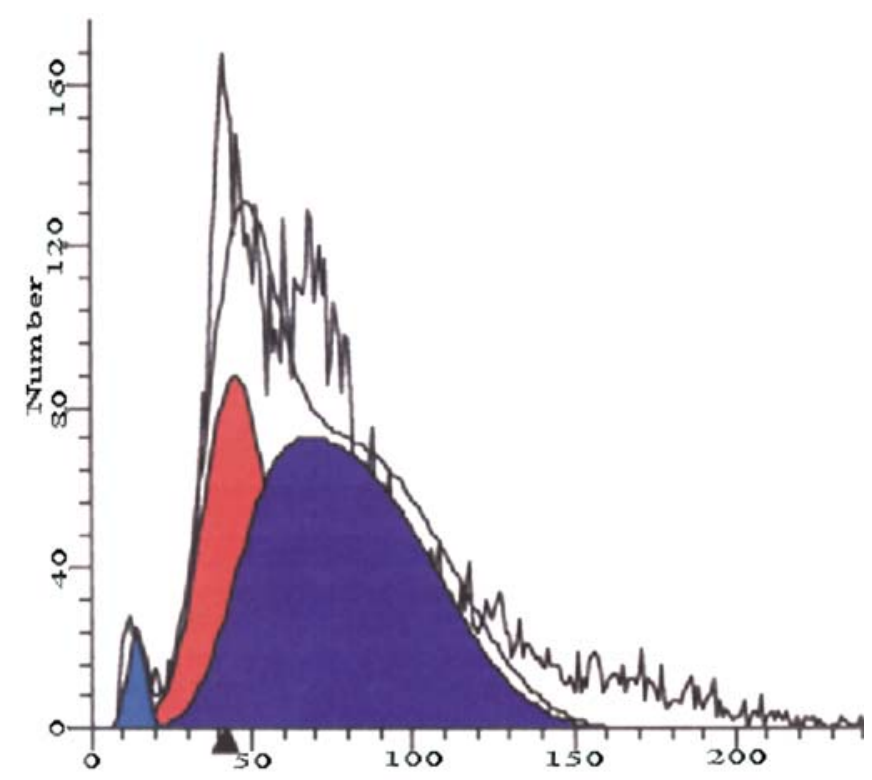

Sample: 1 . G0-G1: $29.14 \%$ at 43.78 , G2-M: $5.44 \%$ at 104.72 Total S-phase: $65.43 \%$, Apoptosis rate: $2.71 \%$

Figure 3. In EGCG $(20 \mu \mathrm{M})$ treatment group, flow cytometry revealed that cell cycle S-phase rate was lower, while apoptosis rate higher than that in PBS treatment group.

GAPDH was used as control. The sequences of probes and primers were as follows: TFPI-2 probe: FAM-TCTGCC CCCAGCAGACAGAGGA-TAMRA; TFPI-2 primer (sense): 5'-TCACGGCCCCTCATGGT-3'; TFPI-2 primer (antisense): 5'-TCTGATCTCATTGGCTTGACACA-3'. 

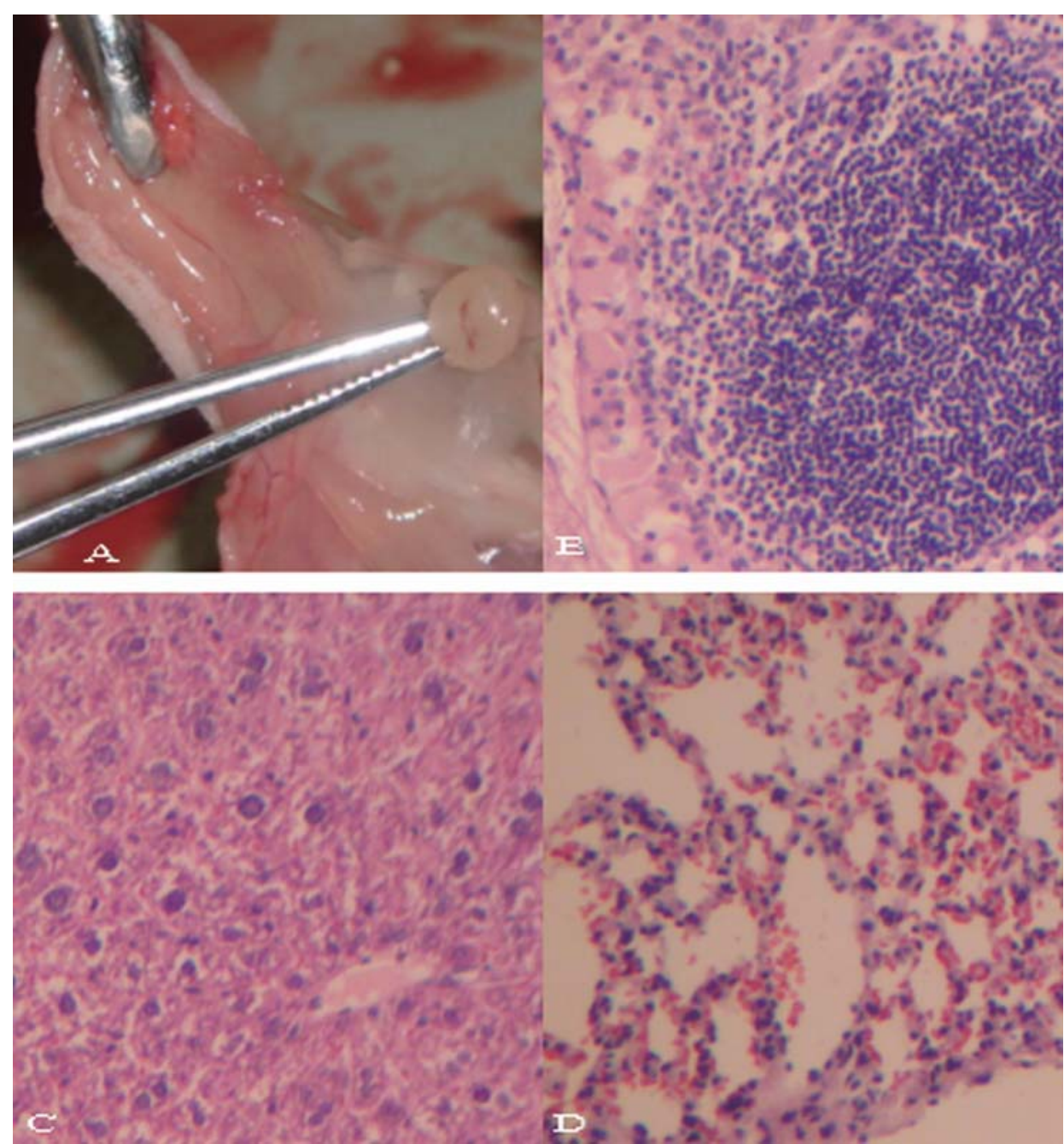

Figure 4. Gross feature of a subcutaneous tumor (A). In all three groups, H\&E staining of a subcutaneous tumor (B), nude mouse liver (C) and lung (D) showed no invasiveness and metastasis of tumor.

GAPDH probe: FAM-AAGGTCATCCCTGAGCTGAATAMRA; GAPDH primer (sense): 5'-ACCCAGAAGAC TGTGGATGG-3'; GAPDH primer (antisense): 5'-TTCTAG ACGGCAGGTCAGGT-3'. TFPI-2 probe for real-time methylation specific PCR: FAM-TTCCAGCTGAACGAGC TCCAAGGC-TAMRA; TFPI-2 primer (sense) for real-time methylation specific PCR: 5'-CCTCTTGCCTTTGGACA TGG-3'; TFPI-2 primer (antisense) for real-time methylation specific PCR: 5'-TCTGCGGCATTTCTCTGGT-3'.

Nude mouse model. Fifteen four-week-old nude mice were maintained in a pathogen-free environment and handled according to the university's guidelines for animal care and use. Nude mice were divided into three groups. Nude mice were injected with $5 \times 10^{6} 786-0$ cells into the right flank. After 6 weeks, the tumor reached $\sim 10 \mathrm{~mm}$ in diameter. Subcutaneous tumor tissue, liver and lung tissue were taken to perform $\mathrm{H} \& \mathrm{E}$ staining. We evaluated the invasiveness of tumor cells among three groups.

\section{Results}

EGCG inhibits proliferation and induces apoptosis of cell line 786-0. MTT and flow cytometry were used to examine

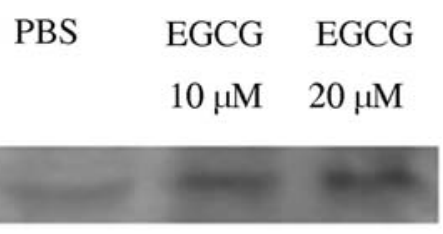

TFPI-2

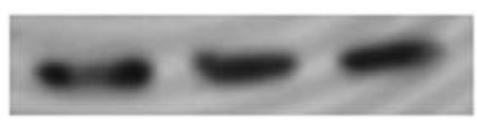

Figure 5. Western blotting revealed increased expression of TFPI-2 after EGCG treatment.

the proliferation status of the cell line 786-0. The mean OD value of $10 \mu \mathrm{M}$ EGCG group, $20 \mu \mathrm{M}$ EGCG group and control group were: $0.526,0.441$ and 0.577 . The inhibition rate of $10 \mu \mathrm{M}$ and $20 \mu \mathrm{M}$ EGCG treatment groups were: 8.8 and $23.6 \%$. S phase rate in EGCG treatment groups was lower than that in control group $(\mathrm{p}<0.05)$ (Figs. 1-3). The mean $\mathrm{S}$ phase rate of $10 \mu \mathrm{M}$ EGCG group, $20 \mu \mathrm{M}$ EGCG group and control group were: 54.31, 60.50 and $71.32 \%$, suggesting that EGCG inhibits growth of cell line 786-0. 


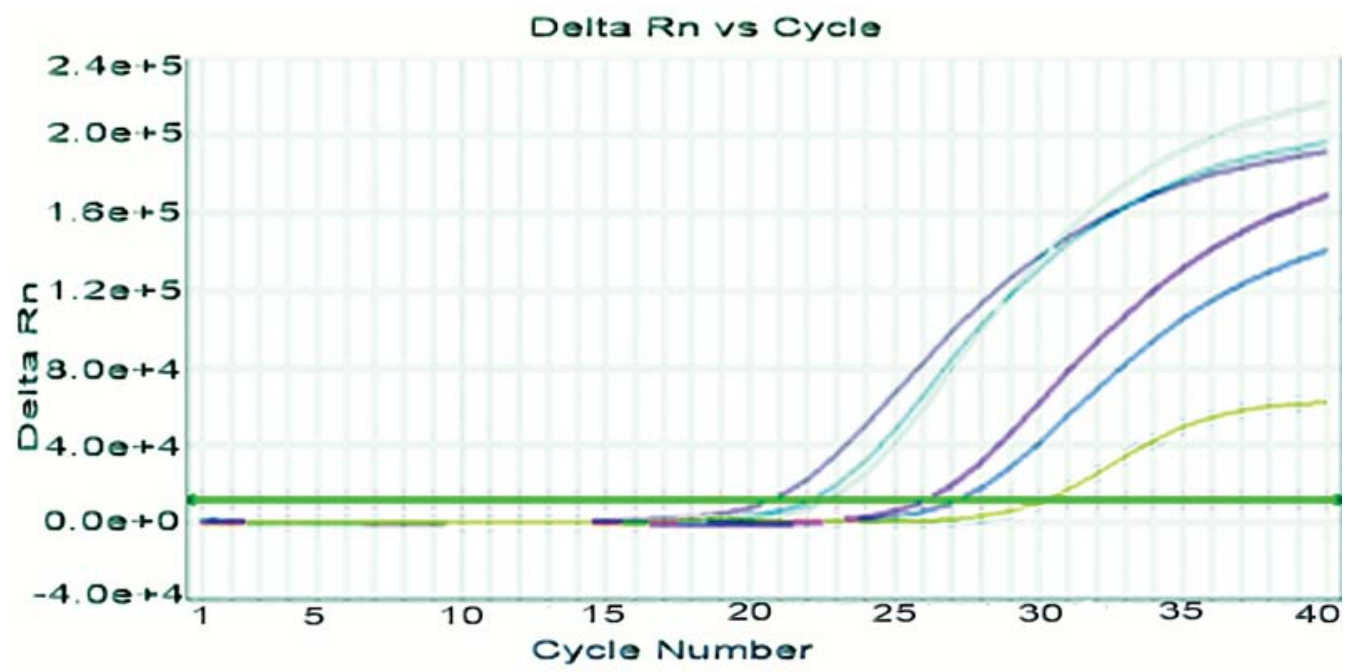

Figure 6. Overexpression of TFPI-2 mRNA after EGCG treatment was detected by using real-time RT-PCR.

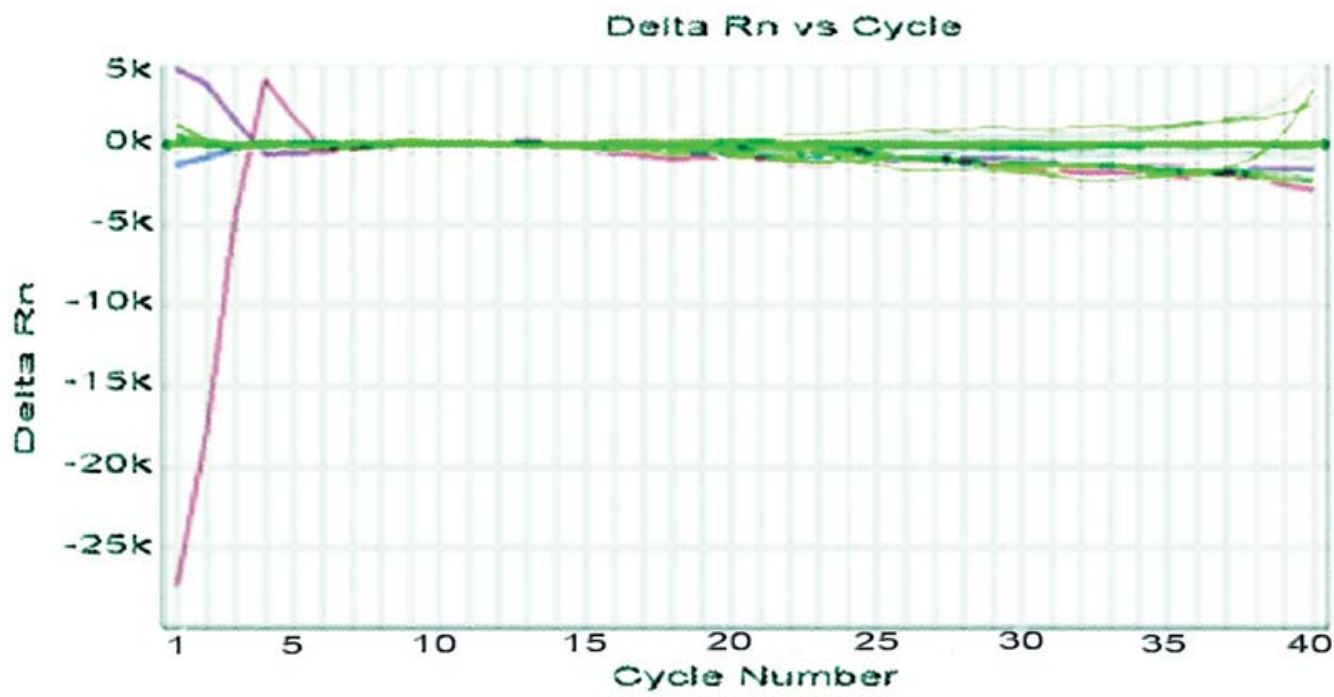

Figure 7. Before and after EGCG treatment, methylation of TFPI-2 gene promoter was undetected by using real-time methylation specific PCR.

Flow cytometry was also used to evaluate apoptosis status of cell line 786-0 (Figs. 1-3). The mean apoptosis rate of $10 \mu \mathrm{M}$ EGCG group, $20 \mu \mathrm{M}$ EGCG group and control group were: $1.09,2.27$ and $0.94 \%$. Apoptosis rate in EGCG treatment groups was higher than that in the control group $(\mathrm{p}<0.05)$.

Invasiveness of tumor cells in vivo. In subcutaneous tumor tissue of nude mice, H\&E staining revealed no invasiveness of tumor cell. We did not find metastasis in nude mouse liver or lung tissue (Fig. 4).

EGCG upregulates expression of TFPI-2. After being treated with $10 \mu \mathrm{M}$ EGCG or $20 \mu \mathrm{M}$ EGCG, Western blotting revealed that TFPI-2 was upregulated by 72.9 and $103 \%$ $(\mathrm{p}<0.05)$ (Fig. 5). Real-time RT-PCR demonstrated that the mean relative expression amount of TFPI- 2 mRNA was: $2.33 \%(10 \mu \mathrm{M}$ EGCG), 4.16\% (20 $\mu \mathrm{M}$ EGCG) and $0.35 \%$ (control group) (Fig. 6). TFPI-2 mRNA expression in EGCG treatment groups was significantly higher than that in the control group $(\mathrm{p}<0.05)$.

Methylation status of TFPI-2 gene promoter. Real-time methylation specific PCR was performed to detect methylation status of TFPI- 2 gene promoter. We could not detect methylation of TFPI-2 promoter in $10 \mu \mathrm{M}$ EGCG group, $20 \mu \mathrm{M}$ EGCG group or the control group (Fig. 7).

\section{Discussion}

The study of plant polyphenols as anticancer agents has increased substantially in recent years, due partly to their profound effects in vitro and in vivo on tumor cell growth, apoptosis and signaling pathways. In addition, epidemiological studies have revealed promising preventative and therapeutic roles for polyphenols. EGCG, the major catechin found in green tea, has been shown to inhibit proliferation 
and induce apoptosis in many cell lines. In the present study, using MTT and flow cytometry, we are the first to show that EGCG can inhibit growth and induces apoptosis in renal cell carcinoma cell line 786-0.

Study has clearly demonstrated that EGCG can inhibit activity of DNMT which causes $\mathrm{CpG}$ demethylation and reactivation of methylation-silenced genes (2). Kinetic studies indicate that EGCG inhibits nuclear DNMT activity competitively with a $\mathrm{Ki}$ of $6.89 \mu \mathrm{M}$. The dominant form of DNMT1 is the main cause, although DNMT $3 \alpha$ and $3 \beta$ may also be present in smaller quantities in the nuclear extracts (3). Molecular modeling studies indicate that EGCG is well accommodated in a hydrophilic pocket of DNMT1. EGCG is effectively tethered within the DNMT1 binding site by at least four hydrogen bonds involving Ser1229, Glu1265, Pro1223 and Cys1225 (4). Many tumor suppressor and receptor genes have been reported to be hypermethylated and transcriptionally silenced during the development of different types of cancers. It is likely that inhibition of DNMT can also prevent the hypermethylation and silencing of these key genes and, therefore, this inhibition would contribute to the treatment and prevention of many tumors.

Besides epigenetic mechanism, the roles of EGCG on tumors include regulation of signal pathway and many proteins: COX-2 (5), MMP-7 (6), EGFR (7), estrogen receptor (8), FGF (9), FOXO3 (10), IGF (11), P57/KIP2 (12), HIF-1 $\alpha$ (13), VEGF (13).

Tissue factor pathway inhibitor-2 (TFPI-2), a member of the Kunitz-type serine proteinase inhibitor family, is a structural homologue of tissue factor pathway inhibitor (TFPI). The expression of TFPI-2 in tumors is inversely related to an increasing degree of malignancy, which may suggest that TFPI-2 can inhibit growth of neoplasms. TFPI-2 is an inhibitor of MMPs (matrix metalloproteinases) which can promote invasiveness of tumor through matrix degradation (14). The levels of TFPI-2 were very low or undetectable in many tumor cells but markedly upregulated in normal cells. TFPI-2 functions in the maintenance of the stability of the tumor environment and inhibits invasiveness and growth of neoplasms, as well as metastases formation. TFPI-2 has also been shown to induce apoptosis and inhibit angiogenesis, which may contribute significantly to tumor growth inhibition. When infected with Raav-TFPI-2, human glioblastoma cell line SNB19 showed decreased formation of microvessels (15). Upregulation of TFPI-2 expression in tumor tissue inhibits invasion, tumor growth and metastasis, which creates a novel possibility of cancer treatment.

Hypermethylation of TFPI-2 promoter $\mathrm{CpG}$ islands in human cancers and cancer cell lines was demonstrated to be responsible for down regulation of mRNA encoding TFPI-2 and decreased or abolished synthesis of TFPI-2 protein during cancer progression. The finding was associated with increased cancer growth and invasion. TFPI-2 methylation was detected in $29 \%$ metastatic melanoma specimens, while it was not detected in all primary melanoma specimens (16). Immunochemically, all melanoma specimens with TFPI-2 promoter methylation lacked immunoreactivity for TFPI-2 (16). In NSCLC (non-small cell lung cancer), decreased TFPI-2 expression and hypermethylation were more frequently associated with stage III and IV of the disease. Approximately one half of NSCLC cases with silenced TFPI-2 gene were lymph node-positive (17). TFPI-2 methylation was observed in all cases of esophageal carcinoma cell lines (18). Aberrant methylation of TFPI-2 was detected in as many as $73 \%$ of pancreatic cancer xenografts and primary pancreatic adenocarcinomas, and was more likely in old patients with pancreatic cancer. Hypermethylation of TFPI-2 was significantly associated with progression of primary pancreatic ductal neoplasms (19). The aberrant methylation rate of TFPI-2 in pure pancreatic juice aspired endoscopically from patients was as high as $100 \%$, promoter methylation of TFPI-2 in the pure pancreatic juice may be an effective marker in diagnosis and progression of pancreatic cancer (20). TFPI-2 promoter methylation was detected in $80 \%$ of hepatocellular carcinoma cell lines and $47 \%$ of human hepatocellular carcinoma, overexpression of TFPI-2 significantly suppressed the proliferation and invasiveness of hepatocellular carcinoma cells, TFPI-2 is a candidate tumor suppressor gene in human hepatocellular carcinoma (21).

Besides epigenetic basis, TFPI-2 is also associated with genetic changes in different cancers (e.g., head and neck carcinomas, gastric, colon, prostate, vesicular, ovarian and testicular cancer, malignant melanoma, and glial neoplasms) (22).

Our previous study showed lower expression of TFPI-2 in renal cell carcinoma compared to normal kidney. The expression of TFPI-2 and stage of renal cell carcinoma showed a negative correlation. The relationship between expression of TFPI-2 and apoptosis index of renal cell carcinoma had a positive correlation. Expression of TFPI- 2 mRNA and protein were significantly lower in methylated tumors than those in demethylated tumors.

Our present study demonstrated that EGCG can upregulate expression of TFPI-2 in the renal cell carcinoma cell line 786-0. Overexpression of TFPI-2 may inhibit growth and induce apoptosis in renal cell carcinoma. EGCG is likely to be an effective agent for renal cell carcinoma. The upregulation of TFPI-2 by EGCG may not be related to the gene promoter methylation status. The exact pathogenesis of upregulation needs to be further investigated.

\section{Acknowledgements}

We thank Dr Duan Ma for technical assistance.

\section{References}

1. Horie N, Hirabayashi N, Takahashi Y, Miyauchi Y, Taguchi H and Takeishi K: Synergistic effect of green tea catechins on cell growth and apoptosis induction in gastric carcinoma cells. Biol Pharm Bull 28: 574-579, 2005.

2. Lee WJ, Shim JY and Zhu BT: Mechanisms for the inhibition of DNA methyltransferases by tea catechins and bioflavonoids. Mol Pharmacol 68: 1018-1030, 2005.

3. Christman JK: 5-Azacytidine and 5-aza-2'-deoxycytidine as inhibitors of DNA methylation: mechanistic studies and their implications for cancer therapy. Oncogene 21: 5483-5495, 2002.

4. Fang MZ, Wang Y, Ai N, et al: Tea Polyphenol (-)-epigallocatechin -3-gallate inhibits DNA methyltransferase and reactivates methylation-silenced genes in cancer cell lines. Cancer Res 63: 7563-7570, 2003.

5. Peng G, Dixon DA, Muga SJ, Smith TJ and Wargovich MJ Green tea polyphenol(-)-epigallocatechin-3-gallate inhibits cyclooxygenase-2 expression in colon carcinogenesis. Mol Carcinog 45: 309-319, 2006. 
6. Kim M, Murakami A and Ohigashi H: Modifying effects of dietary factors on (-)-epigallocatechin-3-gallate-induced promatrix metalloproteinase-7 production in HT-29 human colorectal cancer cells. Biosci Biotechnol Biochem 71: 2442-2450, 2007.

7. Zhang X, Zhang H, Tighiouart M, et al: Synergistic inhibition of head and neck tumor growth by green tea (-)-epigallocatechin-3-gallate and EGFR tyrosine kinase inhibitor. Int J Cancer 123: 1005-1014, 2008.

8. Farabegoli F, Barbi C, Lambertini E and Piva R: (-)-Epigallocatechin-3-gallate downregulates estrogen receptor alpha function in MCF-7 breast carcinoma cells. Cancer Detect Prev 31: 499-504, 2007.

9. Sukhthankar M, Yamaguchi K, Lee SH, Mcentee MF, Eling TE, Hara Y and Baek SJ: A green tea component suppresses posttranslational expression of basic fibroblast growth factor in colorectal cancer. Gastroenterology 134: 1972-1980, 2008.

10. Belguise K, Guo S and Sonenshein GE: Activiation of FOXO3a by the green tea polyphenol epigallocatechin-3-gallate induces estrogen receptor and expression reversing invasive phenotype of breast cancer cells. Cancer Res 67: 5763-5770, 2007.

11. Li M, He Z, Ermakova S, et al: Direct inhibition of insulin-like growth factor-1 receptor kinase activity by (-)-epigallocatechin3 -gallate regulates cell transformation. Cancer Epidemiol Biomarkers Prev 16: 598-605, 2007.

12. Yamamoto T, Digumarthi H, Aranbayeva Z, et al: EGCGtargeted p57/KIP2 reduces tumorigenicity of oral carcinoma cells: role of c-Jun N-terminal kinase. Toxicol Appl Pharmacol 224: 318-325, 2007

13. Zhang Q, Tang X, Lu Q, Zhang Z, Rao J and Le AD: Green tea extract and (-)-epigallocatechin-3-gallate inhibit hypoxia- an serum-induced HIF-1 $\alpha$ protein accumulation and VEGF expression in human cervical carcinoma and hepatoma cells Mol Cancer Ther 5: 1227-1238, 2006.

14. Rollin J, Regina S, Vourch P, Lochmann S, Blechet C, Reverdiau P and Gruel Y: Influence of MMP-2 and MMP-9 promoter polymorphisms on gene expression and clinical outcome of non-small cell lung cancer. Lung Cancer 56: 273-280, 2007
15. Yanamandra N, Kondraganti S, Gondi CS, Gujrti M, Olivero WC, Dinh DH and Rao JS: Recombinant adeno-associated virus (rAAV) expressing TFPI-2 inhibits invasion, angiogenesis and tumor growth in a human glioblastoma cell line. Int J Cancer 115: 998-1005, 2005

16. Nobeyama Y, Okochi-Takada E, Furuta J, et al: Silencing of tissue factor pathway inhibitor-2 gene in malignant melanomas. Int J Cancer 121: 301-307, 2007.

17. Rollin J, Iochmann S, Blechet C, et al: Expression and methylation status of tissue factor pathway inhibitor- 2 gene in non-small-cell lung cancer. Br J Cancer 92: 775-783, 2005.

18. Seiner FA, Hong JA, Fischette MR, et al: Sequential 5-Aza 2'-deoxycytidine/depsipeptide FK228 treatment induces tissue factor pathway inhibitor 2 (TFPI-2) expression in cancer cells. Oncogene 24: 2386-2397, 2005.

19. Sato N, Parker AR, Fukushima N, Miyagi Y, IacobuzioDonahue CA, Eshleman JR and Goggins M: Epigenetic inactivation of TFPI-2 as a common mechanism associated with growth and invasion of pancreatic ductal adenocarcinoma. Oncogene 24: 850-858, 2005.

20. Jiang P, Watanabe H, Okada G, et al: Diagnostic utility of aberrant methylation of tissue factor pathway inhibitor 2 in pure pancreatic juice for pancreatic carcinoma. Cancer Sci 97: 1267-1273, 2006 .

21. Wong CM, Ng YL, Lee JM, et al: Tissue factor pathway inhibitor-2 as a frequently silenced tumor suppressor gene in hepatocellular carcinoma. Hepatology 45: 1129-1138, 2007.

22. Sierko E, Wojtukiewicz MZ and Kisiel W: The role of tissue factor pathway inhibitor-2 in cancer biology. Semin Thromb Hemost 33: 653-659, 2007. 